\title{
BMJ Open Perceived impacts of the national essential medicines system: a cross- sectional survey of health workers in urban community health services in China
}

\author{
Tao Zhang, ${ }^{1}$ Chaojie Liu, ${ }^{2,3}$ Jianping Ren, ${ }^{1}$ Sheng Wang, ${ }^{1}$ Xianhong Huang, ${ }^{1}$ \\ Qing Guo ${ }^{4}$
}

To cite: Zhang T, Liu C, Ren J, et al. Perceived impacts of the national essential medicines system: a cross-sectional survey of health workers in urban community health services in China. BMJ Open 2017;7:e014621. doi:10.1136/ bmjopen-2016-014621

- Prepublication history for this paper is available online. To view these files please visit the journal online (http://dx.doi org/10.1136/bmjopen-2016014621).

$\mathrm{TZ}$ and $\mathrm{CL}$ contributed equally.

Received 13 October 2016 Revised 5 May 2017 Accepted 11 May 2017

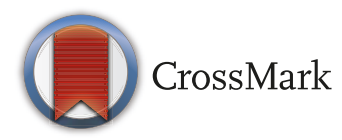

${ }^{1}$ School of Medicine, Hangzhou Normal University, Hangzhou,

China

${ }^{2}$ School of Management, Hubei University of Chinese Medicine, Wuhan, China

${ }^{3}$ School of Psychology and Public Health, La Trobe University, Melbourne, Australia

${ }^{4}$ School of Management,

Zhejiang Chinese Medical University, Hangzhou, China

Correspondence to Jianping Ren; 18768429445@ 163.com

\section{ABSTRACT}

Objectives This study aimed to investigate the perceptions of primary care workers about the impacts of the national essential medicines policy (NEMP).

Setting A cross-sectional questionnaire survey was undertaken in 42 urban community health centres randomly selected from four provinces in China.

Participants 791 primary care workers rated the impacts of the NEMP on a 5-point Likert scale.

Outcome measures An average score for the impacts of the NEMP on four aspects (the practice of health workers, interactions of patients with health workers, operations of health centres and provision of medicines) was calculated, each ranging from 0 to 100 . A higher score indicates a more positive rating. Linear regression models were established to determine the sociodemographic characteristics (region, age, gender, profession, training, income) that were associated with the ratings.

Results The respondents gave an average rating score of $65.61 \pm 11.76,63.17 \pm 13.62,66.35 \pm 13.02$ and $67.26 \pm 11.60$ for the impacts of the NEMP on health workers, patients, health centres and provision of medicines, respectively. Respondents from the central region rated the NEMP higher than those from the eastern and western regions. The pharmacists $(\beta=5.457 \sim 7.558$, $\mathrm{p}<0.001)$ and nurses $(\beta=2.612 \sim 3.107, \mathrm{p}<0.05)$ gave a more positive rating on the NEMP than their physician counterparts. A higher income was found to be associated with a decrease in the NEMP ratings. Repetitive training was a predictor of higher ratings.

Conclusions The NEMP has significant impacts (as perceived by the health workers) on health services delivery in primary care settings. However, the impacts of the NEMP vary by region, professional practice and the income level of health workers. It is important to maintain support from physicians through income subsidies (to compensate for potential loss) and training.

\section{BACKGROUND}

Poor accessibility to quality medicines is a worldwide concern. In 1977, the WHO introduced the concept of essential medicines,
Strengths and limitations of this study

- A cross-sectional questionnaire survey was conducted on a large sample of primary care workers, investigating their views on the impacts of the national essential medicines policy (NEMP). There is paucity in the literature documenting the views of primary care workers on the impacts of the NEMP.

- Multivariate linear regression models were established, identifying key factors associated with the perceived impacts of the NEMP on the practice of health workers, and subsequently on the patients, the primary care institutions and the provision of medicines.

- Although this study was conducted in China, it offers some lessons to the low-income/middleincome countries that are implementing the NEMP.

- This is a cross-sectional study and no causal relationships can be drawn from the findings.

- The study involved only four provinces in China despite a random sampling approach for health facilities. Caution needs to be taken when generalising the findings.

which was defined as 'of utmost importance, basic, indispensable and necessary for the health and needs of the population'. To support its member countries to establish their own national essential medicines policy (NEMP), the WHO developed a model list of essential medicines and published it as a reference for national essential medicines lists (EML). ${ }^{1}$ This is seen as a critical measure, especially for low-income/middle-income nations, to ensure their citizens have equal access to quality medicines. ${ }^{2}$

The WHO EML is updated every 2 years in a transparent manner. The selection of medicines in the EML considers the global health needs of the majority of the population. 
Although the EML has never claimed to meet the needs of everybody, it promises to maximise the benefits of medicines from the perspective of the public in a context of limited resources. The potential value of EML includes reduced costs and a more equitable access to medicines for low-income patients. ${ }^{3}$

China has witnessed increasing financial barriers to the accessibility of medicines over the past three decades, thanks to the perverse incentives resulting from market-oriented reform, which allowed health organisations to retain up to $15 \%$ profit margin on the sales of medicines. Although this reduced the financial burden of the government, healthcare costs escalated rapidly. The policy encouraged health providers to increase the volumes and categories of medicines prescribed and to choose expensive branded medicines over cheaper generic ones. Consumers had to bear the financial burden of exorbitant prescriptions. ${ }^{4}$ It was estimated that medicines accounted for almost $50 \%$ of total healthcare spending in China in the 1990s, ${ }^{5}$ compared with $18 \%$ in the Organisation for Economic Co-operation and Development countries. The cost of medicines per capita grew by $15.3 \%$ annually and reached $¥ 729.3$ (US\$113.1) in 2011 . $^{6}$

In China, the NEMP is considered an effective measure by the government to curb the inflation of medical expenditures and exorbitant prescriptions. ${ }^{78}$ In 2009, the Chinese Government launched the NEMP, which encompasses three broad areas of actions. ${ }^{9-11}$ First, public primary care institutions are only allowed to prescribe medicines from the EML. The first version of the national EML covered 307 generic medicines, including 205 allopathic medicines and 102 traditional Chinese medicines. These medicines were selected by an expert panel based on the common needs of the public (patterns of prevalent diseases), cost-effectiveness, knowledge and skill requirements for primary care workers, and available infrastructure and resources in primary care settings in line with the WHO guidelines. ${ }^{1}$ Due to great regional disparities in social and economic development, provincial governments are allowed to expand the list based on their local demographic needs and economic situations. Second, public primary care institutions are not allowed to mark up medicine prices for profit and must sell medicines at procurement prices (zero-mark-up policy). They have to surrender all revenues collected from medical services (including sales of medicines) to local governments, in exchange for full budget support from local governments. It is estimated that, on average, governmental subsidies contribute $13 \%$ of the budgets for public primary care institutions. ${ }^{78}$ Meanwhile, consumers are encouraged to seek medical attention from primary care institutions through higher reimbursement arrangements for medicines listed in the EML. Third, a regional procurement tendering system is established. The suppliers and prices of medicines are set through the tendering system. Primary care institutions order the medicines they need to stock, usually on a monthly basis.
The assessment of the outcomes of the NEMP has generated a mixed picture. ${ }^{12-14}$ Empirical studies found that the NEMP improved the financial affordability of prescriptions in primary care settings. However, some consumers had to turn to other organisations, usually hospitals, to obtain medicines that were not made available in the EML. The overprescription of antibiotics and injections was found to decline for some diagnoses, but not for others. It is not clear how primary care workers responded to the NEMP and what role they played in these outcomes. Most existing studies have focused on the prescribing behaviours of primary care workers. There is paucity in the literature documenting the views of primary care workers on the impacts of the NEMP. This study aimed to investigate the perceptions of primary care workers and associated factors in regard to the impacts of the NEMP on their practices, and subsequently on the patients, the primary care institutions and the provision of medicines.

\section{METHODS}

A cross-sectional quantitative survey was undertaken on primary care workers in urban community health services.

\section{Measurements}

We developed a questionnaire measuring the impacts of the NEMP as perceived by health workers. The questionnaire comprised items drawn from several other studies. ${ }^{15-18}$ We sought two rounds of expert consultations to modify the questionnaire items. The expert panel included five senior health workers and managers from community health services and five academics who had expertise in health services research. The final agreed version of the questionnaire contained 15 items in the Chinese language, measuring the perceived impacts of the NEMP on four domains: practices of health workers, interactions of patients with health workers, operations of community health centres (CHCs) and provision of medicines. All of the 15 items were designed as close-ended questions, being measured on a 5-point Likert scale.

The perceived impact of the NEMP on the practice of health workers was measured on four aspects: income, workload, work commitment and prescribing behaviours (table 1). For example, 'What do you think about the role of the NEMP in promoting the rational prescription of medicines?'

The perceived impact of the NEMP on patients was measured on three aspects: patient demand, acceptance and trust in prescribers (table 1). Example questions included the following: 'In your opinion, what changes in patient trust in doctors have happened after the implementation of the NEMP?'

Five items were included in measuring the perceived impact of the NEMP on the operations of CHCs: volume of patient visits, patient transfer to hospitals, market share of patients with mild illness, importance of the NEMP and the future development of CHCs (table 1). Example 
Table 1 Factor loadings of questionnaire items (exploratory factor analysis) and Cronbach's $\alpha$ of the four dimensions

\begin{tabular}{|c|c|c|c|c|}
\hline \multirow[b]{2}{*}{ Questionnaire items } & \multicolumn{4}{|c|}{ Impacts of NEMP on } \\
\hline & $\begin{array}{r}\text { Health } \\
\text { workers }\end{array}$ & Patients & CHCs & $\begin{array}{l}\text { Provision of } \\
\text { medicines }\end{array}$ \\
\hline Has NEMP increased income? & 0.529 & & & \\
\hline Has NEMP increased service load? & 0.868 & & & \\
\hline Has NEMP enhanced work commitment? & 0.509 & & & \\
\hline Has NEMP improved rational prescribing? & 0.761 & & & \\
\hline Has NEMP met the needs of residents? & & 0.795 & & \\
\hline Has NEMP been endorsed by residents? & & 0.576 & & \\
\hline Has NEMP improved patient trust in doctors? & & 0.572 & & \\
\hline Has NEMP increased patient visits to CHCs? & & & 0.831 & \\
\hline Has NEMP increased CHC-coordinated patient referral? & & & 0.950 & \\
\hline $\begin{array}{l}\text { Has NEMP increased market share of CHCs for patients with mild } \\
\text { illness? }\end{array}$ & & & 0.752 & \\
\hline How important is NEMP to CHCs? & & & 0.789 & \\
\hline Does NEMP promote development of $\mathrm{CHCs} ?$ & & & 0.732 & \\
\hline Rating on availability of essential medicines & & & & 0.547 \\
\hline $\begin{array}{l}\text { Rating on effectiveness of essential medicines in comparison with } \\
\text { medicines available in the past }\end{array}$ & & & & 0.616 \\
\hline Rating on appropriateness of expenditure on essential medicines & & & & 0.714 \\
\hline Cronbach's $\alpha$ & 0.670 & 0.640 & 0.708 & 0.656 \\
\hline
\end{tabular}

$\mathrm{CHC}$, community health centre; NEMP, national essential medicines policy.

questions included the following: 'In your opinion, will the NEMP be able to support the development of CHCs?'

The perceived impact of the NEMP on the provision of medicines in CHCs was measured based on the availability, effectiveness and expenditure of the medicines (table 1). Example questions included the following: 'How do you rate the effectiveness of the essential medicines in comparison with the medicines that were available in the past?'

The exploratory factor analysis (varimax rotation) ${ }^{19}$ generated a four-factor model and exclusive high loadings $(>0.50)$ of items on their corresponding dimensions. The Cronbach's $\alpha$ coefficients for the four dimensions fell into the commonly acceptable range of $0.65-0.80$, except for one ( 0.64 for the impact of the NEMP on patients). Considering the small number of items in the scales, the internal consistency of the questionnaire is acceptable. ${ }^{20}$

In addition, we collected sociodemographic information on the respondents, such as age, gender, educational attainment, job position, professional title, work experience and income. These were identified as independent variables based on a previous study undertaken by Song Y and colleagues. ${ }^{16}$

\section{Sampling}

A multistage sampling strategy was adopted. Three provinces were purposively selected first from three different geographical zones: Zhejiang representing the eastern, Jiangxi representing the central and Shaanxi representing the western zones. Then, two municipalities with different socioeconomic development status (one higher and one lower) were identified from each of the provinces: Shaoxing and Lishui in Zhejiang, Nanchang and Jiujiang in Jiangxi, and Xi' an and Ankang in Shaanxi. Because the size of community health services in the western region was relatively smaller compared with their eastern and central counterparts, one additional municipality (Urumqi) in Xinjiang was added to the sample. Six CHCs in each municipality were randomly selected, which resulted in a total of 42 participating CHCs.

We estimated that a sample size of 700 would enable us to detect a difference of 2 (out of a possible score of $100)$ in the dimensional measurement scores based on an anticipated SD of 13, $\alpha$ level (type I error rate) at 0.05 and $\beta$ level (statistical power) at $0.8 .^{19}$ This sample size would also be large enough for us to perform multivariate linear regression analyses for a model containing 32 dichotomous independent variables (table 2). We determined to disseminate 840 questionnaires (20 for each participating $\mathrm{CHC}$ ) to minimise the potential influence of non-responses and invalid responses.

Data were collected over the period from 1 May 2014 to 31 October 2014. Two trained investigators were dispatched to each CHC. About 20 health workers per CHC were invited by the investigators to participate in the survey. The health workers who had direct contact with patients were eligible to participate in this study. These 


\begin{tabular}{lc} 
Table 2 & Demographic characteristics of respondents \\
\hline Characteristics of respondents & N (\%) \\
\hline Regions \\
Eastern \\
Central & $275(34.8)$ \\
Western & $246(31.1)$ \\
Sex & $270(34.1)$ \\
Male & \\
Female & $253(32.3)$ \\
\hline
\end{tabular}

\section{Age (years)}

$\begin{array}{lc}\leq 25 & 105(13.3) \\ 26-40 & 401(50.8) \\ 41-55 & 225(28.5) \\ \geq 56 & 58(7.4)\end{array}$

\section{Education}

$\begin{array}{lc}\text { High school } & 26(3.3) \\ \text { Vocational certificate } & 134(17.0) \\ \text { Associate's degree } & 317(40.3) \\ \text { Bachelor's degree or higher } & 310(39.4)\end{array}$

Work experience (years)

\begin{tabular}{|lc|}
\hline$\leq 10$ & $324(41.1)$ \\
\hline $11-20$ & $204(25.9)$ \\
\hline $21-30$ & $155(19.7)$ \\
$\geq 31$ & $105(13.3)$ \\
\hline Division & \\
\hline Internal medicine & $88(11.1)$ \\
\hline Surgical department & $35(4.4)$ \\
\hline Gynaecology and obstetrics & $51(6.5)$ \\
\hline Paediatrics & $14(1.8)$ \\
\hline General practice & $155(19.6)$ \\
\hline Traditional Chinese medicine & $49(6.2)$ \\
\hline Preventive care & $63(8.0)$ \\
\hline Others & $335(42.4)$ \\
\hline
\end{tabular}

Profession

\begin{tabular}{lc} 
Physician & $327(41.3)$ \\
Nurse & $237(30.0)$ \\
\hline Public health worker & $25(3.2)$ \\
\hline Pharmacist & $86(10.9)$ \\
Allied health & $116(14.7)$ \\
Professional title & \\
Junior & $368(46.7)$ \\
Middle & $279(35.4)$ \\
Senior & $61(7.7)$ \\
Others & $80(10.2)$ \\
Annual income $(¥ 1000)$ & \\
$<20$ & $178(22.5)$ \\
$20-$ & $432(54.7)$ \\
\hline
\end{tabular}

Continued

\begin{tabular}{|cc|}
\hline Table 2 & Continued \\
\hline Characteristics of respondents & $\mathbf{N}(\%)$ \\
\hline $50-$ & $160(20.3)$ \\
$\geq 80$ & $20(2.5)$ \\
National essential medicines policy training (times) \\
0 & $226(28.8)$ \\
1 & $211(26.8)$ \\
2 & $159(20.2)$ \\
$\geq 3$ & $190(24.2)$ \\
\hline
\end{tabular}

included physicians, nurses and allied health workers. They were approached at various service points, including medical consultation rooms, nursing stations, rehabilitation services, and pathology and imaging services. The invited participants involved all units in the selected CHCs. We approached potential participants across the entire working time to maximise the chance of capturing a representative sample. About 1300 health workers from the 42 participating CHCs were eligible for this study. The invited participants represented more than $60 \%$ of all eligible participants. Of those invited participants, 791 $(94.17 \%)$ returned valid questionnaires for data analyses. The excluded questionnaires contained incomplete data on the four domains of impact measurements.

\section{Data collection}

The questionnaires were handed over to the participants by the investigators. The investigators did not know any of the potential participants. Participation in the survey was completely voluntary. The participants were asked to read the informed consent letter and gave oral consent before they filled out the questionnaires. The survey was anonymous and the return of the questionnaires was deemed as informed consent. Ethics approval was obtained from Hangzhou Normal University.

\section{Data analysis}

The item responses were transformed to a score ranging from 0 to 100 before they were added up and an average score was calculated for each domain of the measured impacts. A higher score indicates a more positive perception of the respondents on the impacts of the NEMP. No weights were given to the items due to a lack of evidence to support such an exercise.

The four domains of impact measurements met the assumptions of parametric tests. Student's t-tests (for two-group comparisons) or analysis of variance (for multiple-group comparisons) were performed to test the statistical differences in the impact scores across the different sociodemographic characteristics of the respondents. Multivariate linear regression models were established with the four domains of perceived impacts serving as dependent variables and the sociodemographic characteristics of respondents as independent variables. All of the independent variables were categorised into 
groups and transformed into dichotomous measurements in the regression models. We used the ENTER approach in the modelling, with a $p$ value of less than 0.05 being considered as statistically significant. We also conducted logistic regression analyses by recoding the four domains of perceived impacts into dichotomous variables (using average values as a cut-off point).

The data were entered into EpiData 3.1. A double entry strategy was adopted to ensure the accuracy of data input. The statistical analyses were performed using IBM SPSS Statistics V.20.0.

\section{RESULTS}

\section{Sociodemographic characteristics of respondents}

About $68 \%$ of the respondents were women. Half were in the age range between 26 and 40 years. The majority $(80 \%)$ had attained a university degree or associate's degree. Slightly more than $40 \%$ of the respondents had work experience of less than 10 years. More than $77 \%$ earned an annual income less than $¥ 50000$ (US\$7754). The CHCs offered a wide range of specialised medical services, with general practice being the largest, followed by internal medicine. About $20 \%$ of the respondents worked in the department of general practice. NEMP training was offered to more than $70 \%$ of the respondents (table 3).

\section{Perceived impacts of the NEMP}

On average, the respondents gave a rating score of $65.61 \pm 11.76,63.17 \pm 13.62,66.35 \pm 13.02$ and $67.26 \pm 11.60$ for the impacts of the NEMP on the practice of health workers, interactions of patients with health workers, operations of CHCs and provision of medicines, respectively.

The perceived impacts varied with the sociodemographic characteristics of the respondents (table 4). Overall, the participants working in the eastern zone gave lower ratings than those working in the central or western zone $(\mathrm{p}<0.01)$. Respondents of a younger $(\leq 25$ years $)$ or older ( $\geq 56$ years) age rated the impacts higher than those in the middle age range $(\mathrm{p}<0.01)$. The respondents with a university degree rated the impacts lower than their less educated colleagues $(p<0.05)$. The pharmacists gave higher scores compared with their professional colleagues $(\mathrm{p}<0.05)$. The highest rating was given by those with more than 30 years of work experience $(p<0.05)$. The respondents working in the departments of 'Traditional Chinese Medicine' and 'Preventive Care' gave higher rating scores than their colleagues working in other departments $(p<0.01)$. The rating scores decreased with a rise in the income of respondents $(\mathrm{p}<0.001)$.

Gender difference in the ratings was found only in the domain 'provision of medicines', with female respondents giving a higher score than male respondents $(\mathrm{p}=0.001)$. The participants with a senior title gave a higher rating score for the perceived impact of the NEMP on patient interactions with health workers $(p=0.046)$, but not in other domains $(p>0.2)$. A slight increase in the ratings on the impact of the NEMP on the practice of health workers $(p=0.019)$ and possibly also on 'provision of medicines' $(p=0.05)$ was found with increased NEMP training.

\section{Factors associated with perceived impacts: results of multivariate linear regression analyses}

Age, education and work experience were no longer predictors of the impact ratings after controlling for other factors.

Regional differences in the ratings remained (table 2). Compared with the respondents working in the central zone, lower perceived impact scores were given by those living in the eastern zone (on health workers, patients and health centres) and those living in the western zone (on health centres and provision of medicines).

The pharmacists gave a more positive rating on all four domains compared with their physician counterparts $(\beta=5.457 \sim 7.558, \mathrm{p}<0.001)$. The nurses also gave more positive ratings on three domains $(\beta=2.612 \sim 3.107$ for health workers, health centres and provision of medicines, $\mathrm{p}<0.05)$ compared with the physicians. Compared with the respondents working in the departments of internal medicine, those in the surgical departments gave a lower rating on the impact of the NEMP on the practice of health workers $(\beta=-5.139, p=0.023)$; by contrast, those in the departments of Chinese medicine gave a higher rating on the impact of the NEMP on patient interactions with health workers $(\beta=6.384, p=0.007)$. A senior professional title was a predictor of higher ratings on the impact of the NEMP on patients $(\beta=6.150, p=0.006)$.

A higher income was associated with a decrease in the ratings on all four domains. Repetitive training was a predictor of higher ratings (table 2). The logistic regression analyses yielded similar results as those found in the linear regression models, with profession, income, training and region being identified as significant predictors of perceived impacts of the NEMP.

\section{DISCUSSION}

The NEMP aims to improve public accessibility to quality and cost-effective medicines. ${ }^{21}$ The success or otherwise of the NEMP, however, depends on the support of primary care organisations and practitioners. ${ }^{22}$ This study demonstrates that the perceptions of health workers regarding the impacts of the NEMP vary by the socioeconomic status and the professional characteristics of health workers. Clearly, the NEMP is closely associated with the interests of health workers in primary care settings. ${ }^{23} 24$

The respondents working in the eastern zone and the western zone perceived lower impacts of the NEMP than their colleagues working in the central zone. This indicates a possibility of reduction of regional disparity. Under the NEMP, local governments are allowed to expand, but not shrink, the varieties of listed medicines. Overall, the eastern zone in China is the most developed and densely populated, whereas the western zone is the 
Table 3 Perceived impact scores of the NEMP and their associations with the sociodemographic characteristics of respondents

\section{Characteristics of respondents}

Health workers

Patients

CHCs

\section{Region}

\begin{tabular}{llllc} 
Eastern & $61.02 \pm 10.54$ & $58.58 \pm 12.14$ & $62.21 \pm 13.06$ & $65.43 \pm 10.58$ \\
Central & $68.64 \pm 10.41$ & $66.97 \pm 12.92$ & $70.80 \pm 10.61$ & $69.38 \pm 10.72$ \\
Western & $67.58 \pm 12.67$ & $64.40 \pm 14.36$ & $66.53 \pm 13.65$ & $67.19 \pm 13.02$ \\
F & 35.744 & 28.138 & 30.262 & 37.654 \\
p & 0.000 & 0.000 & 0.000 & 0.000 \\
Sex & & & & \\
Male & $65.32 \pm 12.79$ & $62.81 \pm 14.11$ & $65.31 \pm 13.48$ & $65.11 \pm 13.16$ \\
Female & $65.71 \pm 11.17$ & $63.24 \pm 13.30$ & $66.82 \pm 12.72$ & $68.23 \pm 10.51$ \\
t & -0.422 & -0.413 & -1.485 & -3.301 \\
\hline P & 0.673 & 0.679 & 0.138 & 0.001
\end{tabular}

\section{Age (years)}

\begin{tabular}{|c|c|c|c|c|}
\hline$\leq 25$ & $69.19 \pm 9.28$ & $69.29 \pm 12.46$ & $69.79 \pm 8.98$ & $69.78 \pm 10.50$ \\
\hline $26-40$ & $64.61 \pm 11.26$ & $61.36 \pm 13.52$ & $65.84 \pm 12.91$ & $66.83 \pm 11.14$ \\
\hline $41-55$ & $64.93 \pm 12.89$ & $62.50 \pm 13.25$ & $64.54 \pm 14.47$ & $66.07 \pm 12.42$ \\
\hline$\geq 56$ & $68.71 \pm 13.13$ & $67.39 \pm 13.99$ & $70.76 \pm 12.36$ & $70.23 \pm 12.56$ \\
\hline $\mathrm{F}$ & 5.893 & 11.909 & 6.419 & 3.918 \\
\hline $\mathrm{p}$ & 0.001 & 0.000 & 0.000 & 0.009 \\
\hline \multicolumn{5}{|l|}{ Education } \\
\hline High school & $65.96 \pm 9.28$ & $63.78 \pm 6.64$ & $68.77 \pm 11.42$ & $68.20 \pm 10.88$ \\
\hline Vocational certificate & $67.63 \pm 11.17$ & $65.72 \pm 12.76$ & $67.15 \pm 13.54$ & $68.59 \pm 11.43$ \\
\hline Associate's degree & $66.31 \pm 12.35$ & $64.06 \pm 14.54$ & $67.73 \pm 12.44$ & $68.12 \pm 11.97$ \\
\hline $\begin{array}{l}\text { Bachelor's degree or } \\
\text { higher }\end{array}$ & $64.11 \pm 11.45$ & $61.18 \pm 13.25$ & $64.46 \pm 13.39$ & $65.85 \pm 11.27$ \\
\hline $\mathrm{F}$ & 3.372 & 4.253 & 3.841 & 2.751 \\
\hline$p$ & 0.018 & 0.005 & 0.010 & 0.042 \\
\hline \multicolumn{5}{|c|}{ Work experience (years) } \\
\hline$\leq 10$ & $66.42 \pm 10.70$ & $64.25 \pm 13.40$ & $67.52 \pm 11.77$ & $68.27 \pm 11.01$ \\
\hline $11-20$ & $63.69 \pm 11.30$ & $60.83 \pm 13.60$ & $64.55 \pm 13.56$ & $66.01 \pm 10.65$ \\
\hline $21-30$ & $65.26 \pm 14.06$ & $62.45 \pm 14.55$ & $64.08 \pm 14.87$ & $65.50 \pm 13.16$ \\
\hline$\geq 31$ & $67.48 \pm 11.79$ & $65.56 \pm 12.40$ & $69.65 \pm 13.04$ & $69.29 \pm 12.03$ \\
\hline $\mathrm{F}$ & 3.255 & 3.949 & 6.054 & 3.893 \\
\hline $\mathrm{p}$ & 0.021 & 0.008 & 0.000 & 0.009 \\
\hline \multicolumn{5}{|l|}{ Division } \\
\hline Internal medicine & $65.00 \pm 10.88$ & $61.46 \pm 14.03$ & $64.68 \pm 11.33$ & $66.29 \pm 11.23$ \\
\hline Surgical department & $59.71 \pm 15.71$ & $59.05 \pm 14.02$ & $58.63 \pm 19.43$ & $60.95 \pm 13.44$ \\
\hline $\begin{array}{l}\text { Gynaecology and } \\
\text { obstetrics }\end{array}$ & $60.78 \pm 11.97$ & $61.44 \pm 12.36$ & $62.43 \pm 13.14$ & $66.41 \pm 10.50$ \\
\hline Paediatrics & $57.14 \pm 10.14$ & $56.55 \pm 10.43$ & $60.00 \pm 17.40$ & $64.29 \pm 12.15$ \\
\hline General practice & $66.23 \pm 12.71$ & $62.63 \pm 14.91$ & $67.51 \pm 14.02$ & $66.02 \pm 12.08$ \\
\hline $\begin{array}{l}\text { Traditional Chinese } \\
\text { medicine }\end{array}$ & $67.65 \pm 13.39$ & $68.37 \pm 15.40$ & $68.00 \pm 13.61$ & $69.39 \pm 13.67$ \\
\hline Preventive care & $67.14 \pm 10.38$ & $64.29 \pm 13.17$ & $69.31 \pm 12.62$ & $68.60 \pm 11.60$ \\
\hline Others & $66.61 \pm 10.62$ & $63.87 \pm 12.68$ & $67.15 \pm 11.39$ & $68.44 \pm 10.83$ \\
\hline
\end{tabular}

Continued 


\begin{tabular}{|c|c|c|c|c|}
\hline $\begin{array}{l}\text { Characteristics of } \\
\text { respondents }\end{array}$ & Health workers & Patients & CHCs & Provision of medicines \\
\hline $\mathrm{F}$ & 4.420 & 2.523 & 4.129 & 2.877 \\
\hline $\mathrm{p}$ & 0.000 & 0.014 & 0.000 & 0.006 \\
\hline \multicolumn{5}{|l|}{ Profession } \\
\hline Physician & $63.93 \pm 12.63$ & $62.05 \pm 114.13$ & $64.77 \pm 13.98$ & $65.18 \pm 12.47$ \\
\hline Nurse & $66.34 \pm 10.58$ & $63.33 \pm 13.11$ & $67.93 \pm 12.94$ & $69.12 \pm 10.08$ \\
\hline Public health worker & $65.40 \pm 7.63$ & $64.33 \pm 15.87$ & $65.44 \pm 11.88$ & $64.80 \pm 12.25$ \\
\hline Pharmacist & $71.11 \pm 12.16$ & $67.25 \pm 14.07$ & $71.39 \pm 10.86$ & $71.92 \pm 11.55$ \\
\hline Allied health & $64.91 \pm 10.67$ & $62.75 \pm 11.80$ & $64.10 \pm 10.65$ & $66.43 \pm 10.37$ \\
\hline $\mathrm{F}$ & 6.860 & 2.562 & 6.300 & 8.309 \\
\hline $\mathrm{p}$ & 0.000 & 0.037 & 0.000 & 0.000 \\
\hline \multicolumn{5}{|l|}{ Professional title } \\
\hline Junior & $65.96 \pm 11.54$ & $62.68 \pm 14.12$ & $66.72 \pm 12.51$ & $67.64 \pm 11.76$ \\
\hline Middle & $64.69 \pm 11.71$ & $62.32 \pm 13.49$ & $65.49 \pm 13.83$ & $66.62 \pm 11.46$ \\
\hline Senior & $67.54 \pm 14.91$ & $65.98 \pm 13.08$ & $68.27 \pm 14.89$ & $68.11 \pm 12.52$ \\
\hline Others & $65.81 \pm 10.14$ & $66.14 \pm 11.04$ & $66.50 \pm 10.37$ & $67.17 \pm 10.86$ \\
\hline $\mathrm{F}$ & 1.228 & 2.671 & 0.943 & 0.525 \\
\hline$p$ & 0.299 & 0.046 & 0.419 & 0.665 \\
\hline \multicolumn{5}{|c|}{ Annual income $(¥ 1000)$} \\
\hline$<20$ & $69.97 \pm 10.05$ & $68.60 \pm 12.30$ & $69.93 \pm 10.90$ & $69.71 \pm 10.77$ \\
\hline $20-$ & $65.95 \pm 11.77$ & $63.74 \pm 13.60$ & $67.40 \pm 13.17$ & $67.86 \pm 12.08$ \\
\hline $50-$ & $61.31 \pm 11.22$ & $57.13 \pm 12.46$ & $63.96 \pm 10.37$ & $61.23 \pm 12.28$ \\
\hline$\geq 80$ & $55.25 \pm 11.75$ & $51.25 \pm 7.78$ & $54.40 \pm 14.24$ & $59.33 \pm 8.89$ \\
\hline $\mathrm{F}$ & 22.267 & 27.751 & 20.751 & 10.846 \\
\hline $\mathrm{p}$ & 0.000 & 0.000 & 0.000 & 0.000 \\
\hline \multicolumn{5}{|l|}{ NEMP training (times) } \\
\hline 0 & $64.09 \pm 11.13$ & $62.41 \pm 12.02$ & $65.04 \pm 12.28$ & $66.37 \pm 10.44$ \\
\hline 1 & $65.05 \pm 10.10$ & $63.39 \pm 13.69$ & $66.30 \pm 11.58$ & $66.86 \pm 10.55$ \\
\hline 2 & $66.42 \pm 11.71$ & $63.10 \pm 13.17$ & $66.14 \pm 11.03$ & $66.88 \pm 11.34$ \\
\hline$\geq 3$ & $67.51 \pm 13.81$ & $64.04 \pm 15.66$ & $68.53 \pm 14.53$ & $69.33 \pm 13.80$ \\
\hline $\mathrm{F}$ & 3.351 & 0.506 & 2.605 & 2.642 \\
\hline$p$ & 0.019 & 0.678 & 0.051 & 0.050 \\
\hline
\end{tabular}

$\mathrm{CHC}$, community health centre; NEMP, national essential medicines policy.

least developed and sparsely populated. Understandably, the central region that sits in the middle may have a greater financial capacity than their western poorer counterparts to ensure full implementation of the NEMP. In the western region, financial limitations may jeopardise the supply of essential medicines. A recent study revealed that the supply of essential medicines by pharmaceutical suppliers is shaped by prices and volumes of orders. The low population density, the small size of CHCs and the high likelihood of procuring cheaper medicines in the western region can be detrimental to the supply of essential medicines. ${ }^{25}$ By contrast, the restrictions on the varieties of medicines imposed by the NEMP may have a negative effect on the readily available prescribing services in the more affluent regions (such as those in the eastern zone). Indeed, some CHCs complained about the restrictions as they prompted consumers to bypass community health services. ${ }^{26}$

The impacts of the NEMP are likely to be associated with the nature of professional practices. We found that the pharmacists and nurses gave a more positive rating on the impacts of the NEMP than their physician colleagues. Previous studies showed that doctors are more likely than others to notice the unmet consumer needs of medicines, ${ }^{24}{ }^{27}$ which may result in some negative perceptions of the NEMP. Doctors have to struggle between the demands of consumers and the restrictions of prescriptions imposed by the NEMP. ${ }^{28}$ A study in three 
Table 4 Predictors of perceived impacts of the NEMP: multivariate linear regression models

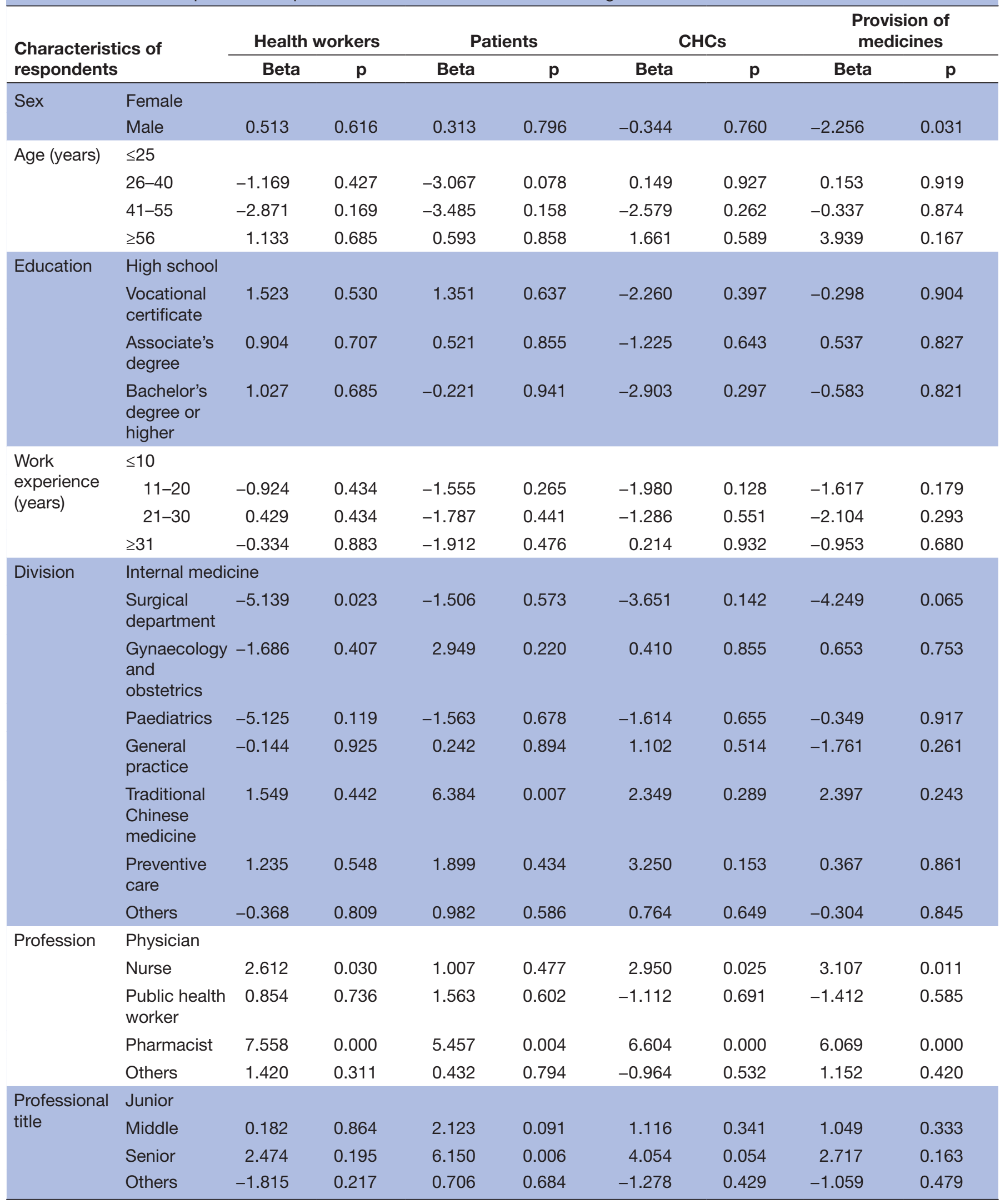


Table 4 Continued

\begin{tabular}{|c|c|c|c|c|c|c|c|c|c|}
\hline \multirow{2}{*}{\multicolumn{2}{|c|}{$\begin{array}{l}\text { Characteristics of } \\
\text { respondents }\end{array}$}} & \multicolumn{2}{|c|}{ Health workers } & \multicolumn{2}{|c|}{ Patients } & \multicolumn{2}{|c|}{ CHCs } & \multicolumn{2}{|c|}{$\begin{array}{c}\text { Provision of } \\
\text { medicines }\end{array}$} \\
\hline & & \multirow[t]{2}{*}{ Beta } & \multirow[t]{2}{*}{$\mathbf{p}$} & \multirow[t]{2}{*}{ Beta } & \multirow[t]{2}{*}{$\mathbf{p}$} & \multirow[t]{2}{*}{ Beta } & \multirow[t]{2}{*}{$\mathbf{p}$} & \multirow[t]{2}{*}{ Beta } & \multirow[t]{2}{*}{$\mathbf{p}$} \\
\hline Annual & $<20$ & & & & & & & & \\
\hline income & $20-$ & -2.420 & 0.038 & -3.052 & 0.027 & -1.031 & 0.423 & -0.862 & 0.469 \\
\hline & $50-$ & -3.330 & 0.050 & -7.722 & 0.000 & -4.872 & 0.009 & -4.389 & 0.011 \\
\hline & $\geq 80$ & -9.990 & 0.001 & -14.954 & 0.000 & -12.076 & 0.000 & -9.226 & 0.002 \\
\hline \multirow{4}{*}{$\begin{array}{l}\text { NEMP } \\
\text { training } \\
\text { (times) }\end{array}$} & 0 & & & & & & & & \\
\hline & 1 & 1.648 & 0.126 & 1.892 & 0.137 & 2.119 & 0.074 & 1.617 & 0.141 \\
\hline & 2 & 3.280 & 0.005 & 2.111 & 0.125 & 2.151 & 0.093 & 1.930 & 0.104 \\
\hline & $\geq 3$ & 4.018 & 0.000 & 2.279 & 0.043 & 4.168 & 0.001 & 3.892 & 0.001 \\
\hline \multirow[t]{3}{*}{ Region } & Central & & & & & & & & \\
\hline & Western & -0.691 & 0.487 & -2.132 & 0.069 & -3.671 & 0.001 & -2.055 & 0.043 \\
\hline & Eastern & -5.794 & 0.000 & -3.779 & 0.010 & -5.438 & 0.000 & -1.686 & 0.185 \\
\hline $\mathrm{R}^{2}$ & & 0.191 & & 0.164 & & 0.187 & & 0.134 & \\
\hline \multicolumn{2}{|c|}{$\mathrm{p}$ (model fit) } & & $<0.001$ & & $<0.001$ & & $<0.001$ & & $<0.001$ \\
\hline
\end{tabular}

$\mathrm{CHC}$, community health centres; NEMP, national essential medicines policy.

rural counties in western China reported that $30 \%$ of the prescription medicines in common use were not covered by the EML, whereas $30 \%$ of the medicines listed were rarely prescribed by physicians. ${ }^{24}$

The NEMP gives traditional Chinese medicine special consideration. About one-third of products listed in the EML are traditional Chinese medicines. ${ }^{29}$ The NEMP promotes safe, cheap and less complicated technologies. This may explain why a lower rating was observed from the health workers from the surgical departments, while a higher rating was given by the health workers from the departments of Chinese medicine, compared with those working in the departments of internal medicine.

The potential impact of the NEMP on the revenue of primary care institutions and income of primary care workers has started to attract increasing concerns recently. ${ }^{30}$ In the past, medicine sales comprised a major source of income for primary care workers. The zeromark-up policy as part of the NEMP has inevitably led to a substantial financial loss for primary care institutions. ${ }^{16}$ This has resulted in a $16.9 \%$ drop in medicine expenditure per prescription, ${ }^{11}$ and governmental subsidies may not be enough to make up the revenue loss of primary care institutions. ${ }^{21}$ As a consequence, health workers with a relatively higher income may be disproportionally influenced by the new financial arrangements. In this study, we found that higher income is indeed associated with lower ratings on the NEMP.

This study shows that repeated NEMP training is associated with higher ratings on all four domains of impacts of the NEMP: practices of health workers, interactions of patients with health workers, operations of health centres and provision of medicines. This is consistent with the findings of another study. ${ }^{16}$ Training may help health workers improve their understanding of the NEMP, which in turn may help improve the implementation of the NEMP.

This study has some limitations. The questionnaire was developed by the research team due to the unavailability of an existing instrument, which may limit the comparability of this study with others. The sample involved only four provinces despite a random sampling approach for CHCs. Caution needs to be taken when generalising the findings. The regression models have a relatively small goodness of fit index $\left(\mathrm{R}^{2}\right)$, indicating a limited ability to explain the variations of the dependent variables. However, our intention was not to predict the NEMP ratings. Instead, we aimed to identify factors that may be associated with the NEMP ratings.

\section{CONCLUSIONS}

The study sheds some light on the factors that are associated with the impacts of the NEMP. The NEMP has significant impacts (as perceived by the health workers) on health workers, patients, health organisations and the provision of medicines in primary care settings. However, the impacts vary by region. A more positive impact was perceived by health workers from the central region. The impacts of the NEMP also vary by the nature of professional practices and the income level of health workers. Particular attention should be paid to physicians and those with a higher level of income, because they are more likely to hold a less positive view on the NEMP. It is important to maintain support from physicians. The governmental subsidies should match the loss of revenues of primary care institutions for the benefit of long-term sustainable development. Meanwhile, a more comprehensive solution to help realise the benefits of EML and 
health workers' adherence to EML is needed. Training and management support may be one of the effective measures to attract support from health workers. Performance assessment and financial incentive arrangements should also be aligned with the goals of the NEMP.

Acknowledgements We thank all of the participants and the support of the participating health centres.

Contributors All authors contributed to the study. JR was involved in the design of the study. TZ collected and analysed the research data. TZ and SW wrote the manuscript while $\mathrm{XH}$ and $\mathrm{QG}$ read and revised the manuscript. $\mathrm{CL}$ critically commented and revised the paper. The final version submitted for publication was read and approved by all authors.

Competing interests None declared.

Patient consent Obtained.

Provenance and peer review Not commissioned; externally peer reviewed.

Data sharing statement The data sets analysed during the current study are available from the corresponding author on reasonable request.

Open Access This is an Open Access article distributed in accordance with the Creative Commons Attribution Non Commercial (CC BY-NC 4.0) license, which permits others to distribute, remix, adapt, build upon this work non-commercially, and license their derivative works on different terms, provided the original work is properly cited and the use is non-commercial. See: http://creativecommons.org/ licenses/by-nc/4.0/

(C) Article author(s) (or their employer(s) unless otherwise stated in the text of the article) 2017. All rights reserved. No commercial use is permitted unless otherwise expressly granted.

\section{REFERENCES}

1. Laing R, Waning B, Gray A, et al. 25 years of the WHO essential medicines lists: progress and challenges. Lancet 2003;361:1723-9.

2. Xu W, Xu ZY, Cai GJ, et al. Estimated financing amount needed for essential medicines in China, 2014. Chin Med J 2016;129:716-22.

3. Sharma A, Rorden L, Ewen M, et al. Evaluating availability and price of essential medicines in Boston area (Massachusetts, USA) using WHO/HAl methodology. J Pharm Policy Pract 2016;9:12.

4. Meng Q, Cheng G, Silver L, et al. The impact of China's retail drug price control policy on hospital expenditures: a case study in two Shandong hospitals. Health Policy Plan 2005;20:185-96.

5. Song $\mathrm{Y}$, Bian $\mathrm{Y}$, Petzold $\mathrm{M}$, et al. Effects of the national essential medicine system in reducing drug prices: an empirical study in four Chinese provinces. J Pharm Policy Pract 2014;7:12.

6. Freeman CW, Boynton XL. Implementing Health Care Reform policies in China. Washington, DC: Center for Strategic and International Studies, 2011.

7. Opinions of the Communist Party of China Central Committee and the State Council on deepening the health care system reform. Beijing: State Council, 2009. In Chinese. http://www.nhfpc.gov.cn/ zwgk/jdjd/201304/67700a51f6b0493cb195a3965f22acbf.shtml.

8. Circular concerning issuance of opinions on implementation concerning establishment of China's National Essential Medicine System. Beijing: Ministry of Health, 2009. In Chinese. http://www.nhfpc.gov.cn/zwgk/wtwj/201304/ f2a0d9cbc33f45e091a9d4a936c6fe58.shtml.

9. National essential medicines list for primary healthcare facilities. Beijing: Ministry of Health, 2009. In Chinese. http://www.gov.cn/gzdt/ 2009-08/18/content_1395524.html.
10. Xu S, Bian $\mathrm{C}$, Wang $\mathrm{H}$, et al. Evaluation of the implementation outcomes of the Essential Medicines System in Anhui county-level public hospitals: a before-and-after study. BMC Health Serv Res 2015;15:403.

11. Tian X, Song Y, Zhang X. National Essential Medicines list and policy practice: a case study of China's health care reform. BMC Health Serv Res 2012;12:401.

12. Chen W, Tang S, Sun J, et al. Availability and use of essential medicines in China: manufacturing, supply, and prescribing in Shandong and Gansu provinces. BMC Health Serv Res 2010;10:211.

13. Song $\mathrm{Y}$, Bian $\mathrm{Y}$, Petzold $\mathrm{M}$, et al. The impact of China's national essential medicine system on improving rational drug use in primary health care facilities: an empirical study in four provinces. $B M C$ Health Serv Res 2014;14:507.

14. Zhang X, Wu Q, Liu G, et al. The effect of the National Essential Medicines Policy on health expenditures and service delivery in Chinese township health centres: evidence from a longitudinal study. BMJ Open 2014;4:e006471.

15. Barber SL, Huang B, Santoso B, et al. The reform of the essential medicines system in China: a comprehensive approach to universal coverage. J Glob Health 2013;3:010303.

16. Song Y, Bian Y, Li L. Current perspectives on China's national essential medicine system: primary care provider and patient views. BMC Health Serv Res 2016;16:30.

17. Fang Y, Wagner AK, Yang S, et al. Access to affordable medicines after health reform: evidence from two cross-sectional surveys in Shaanxi Province, western China. Lancet Glob Health 2013;1:e227-e237.

18. Li Y, Ying C, Sufang G, et al. Evaluation, in three provinces, of the introduction and impact of China's National Essential Medicines Scheme. Bull World Health Organ 2013;91:184-94.

19. Lu Y, Hu XM, Huang XL, et al. Job satisfaction and associated factors among healthcare staff: a cross-sectional study in Guangdong Province, China. BMJ Open 2016;6:e011388.

20. Carver CS. You want to measure coping but your protocol's too long: consider the brief COPE. Int J Behav Med 1997;4:92-100.

21. Guan X, Liang $H$, Xue $Y$, et al. An analysis of China's national essential medicines policy. J Public Health Policy 2011;32:305-19.

22. Song $Y$, Bian $Y$. Investigation and survey of effects of national essential drug system on township hospitals in Shandong Province and its policy suggestions. China Pharm 2013;24:693-5.

23. Gong $Y$, Yang C, Yin X, et al. The effect of essential medicines programme on rational use of medicines in China. Health Policy Plan 2016;31:21-7.

24. Xiao $\mathrm{Y}$, Zhao K, Bishai DM, et al. Essential drugs policy in three rural counties in China: what does a complexity Lens add? Soc Sci Med 2013;93:220-8

25. Tang YQ, Liu CJ, Zhang XP. Market response to governmental interventions: a study on availability of essential medicines in primary care institutions in Hubei Province, China. Appl Health Econ Health Policy 2016.

26. Yao Q, Liu C, Ferrier JA, et al. Urban-rural inequality regarding drug prescriptions in primary care facilities - a pre-post comparison of the National essential Medicines scheme of China. Int $J$ Equity Health 2015;14:58

27. Yang S, Lz X, Wang XZ, et al. Analysis on satisfactory degree of essential drug policies among outpatients. Journal of Shandong University 2012;50:124-6.

28. Shi LW, Ma YQ, Xu LP, et al. Php11 review of adjustment of essential medicine list at provincial level in china. Value in Health 2011;14:A14.

29. Ding D, Pan Q, Shan L, et al. Prescribing patterns in Outpatient Clinics of Township Hospitals in China: a comparative study before and after the 2009 Health System Reform. Int J Environ Res Public Health 2016;13:679.

30. Yang LP, Liu CJ, Ferrier A, et al. Implementation of national essential medicine policy and its influencing factors: a cross-sectional study of township hospitals in China. Social Science \& Medicine 2015. 